\title{
Henri Mitterand, Zola tel qu'en lui-même
}

\section{Maria Emanuela Raffi}

\section{(2) OpenEdition}

\section{Journals}

\section{Edizione digitale}

URL: http://journals.openedition.org/studifrancesi/7677

DOI: 10.4000/studifrancesi.7677

ISSN: 2421-5856

\section{Editore}

Rosenberg \& Sellier

\section{Edizione cartacea}

Data di pubblicazione: 1 décembre 2009

Paginazione: 657-658

ISSN: 0039-2944

\section{Notizia bibliografica digitale}

Maria Emanuela Raffi, «Henri Mitterand, Zola tel qu'en lui-même», Studi Francesi [Online], 159 (LIII | III) | 2009, online dal 30 novembre 2015, consultato il 09 janvier 2021. URL: http://

journals.openedition.org/studifrancesi/7677 ; DOI: https://doi.org/10.4000/studifrancesi.7677

\section{Questo documento è stato generato automaticamente il 9 janvier 2021.}

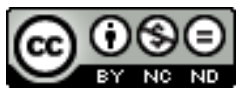

Studi Francesi è distribuita con Licenza Creative Commons Attribuzione - Non commerciale - Non opere derivate 4.0 Internazionale. 


\title{
Henri Mitterand, Zola tel qu'en lui- même
}

\author{
Maria Emanuela Raffi
}

\section{NOTIZIA}

HENRI MITTERAND, Zola tel qu'en lui-même, Paris, PUF, 2009, pp. 216.

1 Sotto molti punti di vista questo saggio costituisce un'autorevole "mise au point" su Zola, prodotto della lunga e fruttuosa frequentazione dell'opera zoliana e dei numerosi saggi critici sull'argomento che uno specialista della qualità di Henri Mitterand ha prodotto nella sua lunga attività critica.

2 Il primo oggetto di puntualizzazione è il concetto di "naturalisme"cui Zola appare indissolubilmente legato. In un'introduzione dal titolo vagamente provocatorio (Pour libérer Zola du 'naturalisme'...) Mitterand indica chiaramente le sue intenzioni: «C'est à cette tentative de relativisation du naturalisme zolien que ce livre s'attache. Relativiser: c'est-à-dire ni prendre pour argent comptant les définitions et les propositions des Romanciers naturalistes et du Roman experimental, ni en denier totalement l'intérêt et la valeur». Su questa linea e sulla parallela valorizzazione «des transformations imposées au réel par l'imaginaire dans le naturalisme de fiction» si muove lo studio nel suo insieme, percorrendo in senso diacronico l'opera zoliana, dalle opere giovanili fino agli ultimi articoli. Già in Différences entre Balzac et moi del 1869, Mitterand rileva, accanto all'idea fondamentale di "peindre une seule famille», la presenza di una «logique de la finalité» che si esprime nei concetti di marche, appetit, élan, fièvre, figure dell'«évasion visionnaire, volontiers épique» da cui nascono le quattro fondamentali forze del "monde à part" zoliano: le Sexe, la Mort, Dieu et l'Art. Poste queste forze e il loro originario e quasi primitivo interagire nell'opera, non ci si può stupire della violenza che essa esprime (Mémoire de la violence), ben diversamente da quanto ci si potrebbe aspettare da una scrittura di paziente riproduzione del reale. I meccanismi di interazione degli individui nella famiglia e nel gruppo sociale che Zola rappresenta nei 
Rougon-Macquart costituiscono una catena ininterrotta di violenze, un «intrigue paroxystique», secondo la definizione di Julia Kristeva, che Mitterand segue con attenzione, mettendo in luce, dietro l'intelligenza dell'immensa analisi sociale, l'emergere dell'arcaico e del profondo, che motiva il piacere della lettura e «nourrit, en pleine modernité, non seulement la mémoire des humains, mais aussi leur pouvoir de sentir, de rêver et de conter».

Le lieu et le sens, ampio capitolo consacrato ai luoghi fisici dell'opera zoliana, prende in esame il secondo elemento del determinismo applicato da Zola ai suoi romanzi: «la matérialité du lieu», che si accompagna alla «matérialité du corps» e produce il costante «enracinement» geografico ed etnografico dei personaggi. Il rapporto di Zola con i luoghi contemporanei, eminentemente urbani, dei suoi romanzi è disegnato da Mitterand con un percorso intertestuale, una sorta di dialogo continuo e serrato con i testi da una parte e con la critica zoliana dall'altra, che porta alla scoperta del fruttuoso incrocio di storia e mito nella presentazione e nella percezione degli spazi zoliani. Sorta di mise en abyme privilegiata di queste tematiche, Le Ventre de Paris rivela in questo modo, al di là dell'analisi della mentalità commerciale dell'epoca e degli elementi di politica, la sua natura d'«histoire d'une pathologie d'espace», storia di un corpo individuale alle prese con la 'prigione metallica' delle Halles.

4 La tesi di un Zola «moderne et paradoxal» che circola per tutto il saggio, consentendo a Mitterand fugaci accostamenti con il surrealismo, è particolarmente presente nel capitolo Le "rêveur définitif» che riprende direttamente una definizione bretoniana e si propone di trattare il linguaggio figurato di Zola, la natura visionaria delle sue immagini, il carattere estremo del suo naturalismo, che forza i propri limiti «pour découvrir les envers, les marges, les déraisons, voire les sortilèges, du naturel». E per arrivare, come i surrealisti, alla rivoluzione.

5 Passage de l'Ouragan sui "dossiers préparatoires" del dramma lirico L'Ouragan e Abymes zoliens sulla pratica pre-gidiana della "mise en abyme" da parte di Zola completano l'analisi formale dei testi zoliani.

6 Due scritti costituiscono infine l'ultima parte del saggio - Vérités - con un contributo sui testi politici di Zola (Face aux pouvoir) e una riflessione chiarificatrice sui rapporti fra Zola e Cézanne e sulla reciproca influenza che i due artisti hanno esercitato, espressione di un'amicizia a tratti problematica ma sempre profonda e fruttuosa. 